\title{
FRACTURE ASSESSMENTS WITH ELASTIC FOLLOW-UP FOR COMBINED PRIMARY AND SECONDARY LOADINGS PART 1: PREDICTIVE MODELS
}

\author{
Document Version \\ Accepted author manuscript
}

Link to publication record in Manchester Research Explorer

Citation for published version (APA):

Lee, J. H., Kim, Y-J., Ainsworth, R., \& Oh, C. Y. (2019). FRACTURE ASSESSMENTS WITH ELASTIC FOLLOWUP FOR COMBINED PRIMARY AND SECONDARY LOADINGS PART 1: PREDICTIVE MODELS. Engineering Fracture Mechanics.

Published in:

Engineering Fracture Mechanics

\section{Citing this paper}

Please note that where the full-text provided on Manchester Research Explorer is the Author Accepted Manuscript or Proof version this may differ from the final Published version. If citing, it is advised that you check and use the publisher's definitive version.

\section{General rights}

Copyright and moral rights for the publications made accessible in the Research Explorer are retained by the authors and/or other copyright owners and it is a condition of accessing publications that users recognise and abide by the legal requirements associated with these rights.

\section{Takedown policy}

If you believe that this document breaches copyright please refer to the University of Manchester's Takedown Procedures [http://man.ac.uk/04Y6Bo] or contact uml.scholarlycommunications@manchester.ac.uk providing relevant details, so we can investigate your claim.

\section{OPEN ACCESS}


Fracture Assessments with Elastic Follow-up for Combined Primary and Secondary Loadings

Part 1: Predictive Models

$$
\text { R A Ainsworth }{ }^{1}, \text { Y-J Kim }{ }^{2}
$$

${ }^{1}$ School of Mechanical, Aerospace \& Civil Engineering, The University of Manchester, Manchester M13 9PL, UK

${ }^{2}$ Department of Mechanical Engineering, Korea University, Anam-Dong, Seongbuk-Gu, Seoul 136-701, South Korea

${ }^{1}$ Corresponding author, email: robert.ainsworth@manchester.ac.uk (R A Ainsworth)

\begin{abstract}
This paper reviews the definition of elastic follow-up starting with that used in creep assessments and seeking parallel definitions for the treatment of combined primary and secondary loadings in fracture assessments. Methods for estimating the elastic follow-up factor for secondary stresses acting alone in cracked structures are then presented. It is shown that elastic follow-up factors can be estimated from elasticplastic estimates of $\mathbf{J}$ for high secondary stress and are weakly dependent on elasticplastic material properties. Potential methods for estimating $\mathrm{J}$ under combined primary and secondary loadings, using the elastic follow-up factor evaluated for secondary stresses acting alone, are then presented. The applicability of these methods is examined in part 2 of this paper by comparison with detailed finite element calculations.
\end{abstract}

Keywords: elastic follow-up, failure assessment diagram, secondary loading 


\section{Nomenclature}

a crack size

A function in Eqs (21-22)

$\mathrm{C}(\mathrm{t})$ transient creep crack tip characterising parameter as a function of time

E Young's modulus

E' Young's modulus in plane stress, E / $\left(1-v^{2}\right)$ in plane strain

$\mathrm{f}, \mathrm{f}_{1}$ failure assessment curve (FAC) in R6, R6 Option 1 FAC

$\mathrm{h}_{1} \quad$ function in eqn (20)

$\mathrm{J} \quad \mathrm{J}$-integral, characterising parameter for elastic-plastic fracture

$\mathrm{J}^{\mathrm{s}} \quad$ value of $\mathrm{J}$ for secondary loading acting alone

$\mathrm{K}_{\mathrm{I}}^{\mathrm{p}} \quad$ linear elastic stress intensity factor for primary loading

$\mathrm{K}_{\mathrm{I}}^{\mathrm{s}} \quad$ linear elastic stress intensity factor for secondary loading

$\mathrm{K}_{\mathrm{J}} \quad$ elastic-plastic stress intensity factor

$\mathrm{K}_{\mathrm{J}}^{\mathrm{s}} \quad$ elastic-plastic stress intensity factor for secondary loading

$\mathrm{L}_{\mathrm{r}} \quad \mathrm{R} 6$ measure of proximity to plastic collapse

$\mathrm{m} \quad$ elastic-plastic stress exponent for power-law plasticity

$\mathrm{t} \quad$ section thickness

$\mathrm{V}$ multiplying factor to incorporate secondary stress effects on $\mathrm{J}$

$\mathrm{V}^{(\mathrm{n})} \quad$ estimates of $\mathrm{V}$ for $\mathrm{n}=1, \ldots, 6$ in Eqs $(17-22)$

$\mathrm{V}_{0} \quad$ value of $\mathrm{V}$ for the secondary stress acting alone

$\mathrm{x} \quad$ variable

Z elastic follow-up factor

$\mathrm{Z}^{\mathrm{s}} \quad$ elastic follow-up factor for secondary loading alone

$\alpha \quad$ multiplying constant in Ramberg-Osgood relationship of Eq. (8)

$\beta \quad$ normalised elastic magnitude of secondary loading

$\Delta \quad$ applied displacement

$\varepsilon \quad$ total strain

$\varepsilon^{\mathrm{pl}} \quad$ plastic strain

$\varepsilon_{\text {ref }} \quad$ strain at reference stress

$\varepsilon_{\text {ref }}^{\mathrm{s}} \quad$ strain at stress $\sigma_{\text {ref }}^{\mathrm{s}}$

$v \quad$ Poisson's ratio

$\sigma_{\text {ref }}$ reference stress

$\sigma_{\text {ref }}^{\mathrm{p}} \quad$ reference stress for primary loading

$\sigma_{\text {ref }}^{\mathrm{s}} \quad$ reference stress for secondary loading

$\sigma_{\text {ref }}^{\text {sel }} \quad$ elastic estimate of secondary reference stress

$\sigma_{\text {ref }}^{0} \quad$ sum of reference stresses for primary and secondary loadings

$\sigma_{\mathrm{y}} \quad$ yield stress 


\section{INTRODUCTION}

For fracture mechanics calculations in the elastic region, the contributions of primary and secondary stresses are simply added to calculate the total stress intensity factor. However, when plasticity occurs, the relative contributions of the primary and secondary loads to the crack driving force change during the loading sequence. In particular, the secondary stress is much less significant after ligament yielding occurs. The treatment of this complex response to secondary stresses in post-yield fracture has been investigated by a number of authors, [1-3] for example. This has led to fitness-for-service codes such as BS7910 [4] and R6 [5] using the elastic stress intensity factor for the secondary stresses multiplied by a factor, $\mathrm{V}$, which changes with load to account for the effects of plasticity on the secondary loads.

In some cases, the crack tip plastic zone remains surrounded by elastic material even at remote stresses approaching the yield stress. This can lead to an increase in the contribution of the secondary stresses to the crack driving force compared to conventional cases where secondary stresses relax with increasing plasticity. This type of response is described as exhibiting elastic follow-up and the treatment of elastic follow-up in fracture mechanics has been addressed in some recent papers $[6$, 7].

The advice in fitness-for-service codes on treatment of elastic follow-up is, however, limited. Treating the secondary loads as primary is a conservative approach where elastic follow-up may be present but may be over-conservative. Detailed elasticplastic analysis may be used to reduce this over-conservatism but simplified methods for estimating $\mathrm{J}$ for cases with elastic follow-up and representing these estimates in terms of the parameter $\mathrm{V}$ are desirable.

To provide guidance on estimation of elastic follow-up factors and associated estimates of $\mathbf{J}$ for cracked components, this paper first reviews the definition of an elastic follow-up factor, $Z$, in Section 2. Then, methods of estimation of $Z$ are reviewed in Section 3 for secondary loading and a simplified estimation approach is presented. The applicability of this estimate for combined primary and secondary loading is discussed in Section 4 where a number of potential estimation methods are presented. Part 2 of this paper [8] examines these estimation methods by comparison with numerical estimates of $\mathrm{Z}$ from analyses of cracked components in order to provide guidance on simplified estimation schemes.

\section{THE DEFINITION OF Z}

The phenomenon of elastic follow-up has been recognized for many years, particularly for high temperature piping systems [9, 10]. It is treated in high temperature assessment procedures such as R5 [11] for both uncracked and cracked bodies. The definition of an elastic follow-up factor, $Z$, is given in terms of the stress relaxation response described by the change of equivalent stress relative to the change of equivalent strain.

In general, $\mathrm{Z}$ depends on the position in a structure at which stress relaxation is evaluated. For combined primary and secondary stresses, the value of $Z$ depends on the secondary stress and the primary stress and also on the material properties such as the creep stress exponent, n. During creep relaxation, as steady state conditions are 
approached, the value of $Z$ defined in terms of total strains continues to increase with increasing time and $Z$ tends to infinity, the value for pure primary load, at long times. A similar definition for cracked components in the elastic-plastic regime has been used, in [6] for example, and is

$$
\mathrm{Z}=\frac{\left[\varepsilon^{\mathrm{pl}}\left(\sigma_{\mathrm{ref}}\right)-\varepsilon^{\mathrm{pl}}\left(\sigma_{\mathrm{ref}}^{\mathrm{s}}\right)-\varepsilon^{\mathrm{pl}}\left(\sigma_{\mathrm{ref}}^{\mathrm{p}}\right)\right]}{\left(\sigma_{\text {ref }}^{0}-\sigma_{\text {ref }}\right) / \mathrm{E}}
$$

This applies for combined loading with superscript pl denoting the plastic component of strain and $\sigma_{\text {ref }}^{0}=\sigma_{\text {ref }}^{\mathrm{p}}+\sigma_{\text {ref }}^{\mathrm{s}}$ being the sum of the primary and secondary reference stress values $\sigma_{\text {ref }}^{\mathrm{p}}, \sigma_{\text {ref }}^{\mathrm{s}}$, respectively, with $\sigma_{\text {ref }}$ being the relaxed reference stress as a result of plastic straining. The primary and secondary reference stresses are defined below, consistent with the approaches in R6. Eq. (1) is evaluated at reference stress levels and hence, in contrast to the approach for creeping structures, is a single value for a cracked structure which describes the relaxation relevant to the crack tip stress and strain fields.

An alternative definition of elastic follow-up factor is given in R5 [11] by subtracting the steady state creep strains from the accumulated creep strain when defining the increment of strain. This has the advantage that it describes only the relaxation of secondary stress and leads to an elastic follow-up factor, here denoted $\mathrm{Z}^{\mathrm{s}}$, which tends to remain constant with time rather than increasing towards the value for primary loading $(\mathrm{Z} \rightarrow \infty)$.

For pure secondary loading in the elastic-plastic regime, a definition of $\mathrm{Z}^{\mathrm{s}}$ consistent with that used in the creep regime is obtained by setting the denominator in Eq. (1) to $\left(\sigma_{\text {ref }}^{\text {sel }}-\sigma_{\text {ref }}^{\mathrm{s}}\right) / \mathrm{E}$ where $\sigma_{\text {ref }}^{\text {sel }}$ is the elastic estimate of secondary reference stress; the numerator in Eq. (1) is replaced by the strain increase at the secondary reference stress relative to its elastic value, i.e. by $\varepsilon\left(\sigma_{\text {ref }}^{\mathrm{s}}\right)-\sigma_{\text {ref }}^{\mathrm{s}} / \mathrm{E}$ where $\varepsilon\left(\sigma_{\text {ref }}^{\mathrm{s}}\right)$ is the total strain at the secondary reference stress, $\sigma_{\text {ref }}^{\mathrm{s}}$. Here,

$$
\sigma_{\text {ref }}^{\mathrm{s}, \mathrm{el}}=\beta \sigma_{\mathrm{y}}
$$

where $\sigma_{\mathrm{y}}$ is the yield stress is used to define the initial magnitude of the elastic secondary stress where the term $\beta$ can alternatively be written as

$$
\beta=\frac{\mathrm{K}_{\mathrm{I}}^{\mathrm{s}}}{\mathrm{K}_{\mathrm{I}}^{\mathrm{p}} / \mathrm{L}_{\mathrm{r}}}
$$

which is the normalised elastic magnitude of secondary loading used in R6 with $\mathrm{K}_{\mathrm{I}}^{\mathrm{p}}, \mathrm{K}_{\mathrm{I}}^{\mathrm{s}}$ being the stress intensity factors for the primary and secondary loads, respectively; $L_{r}$ is the ratio of primary load to limit load with $\sigma_{\text {ref }}^{\mathrm{p}}=\mathrm{L}_{\mathrm{r}} \sigma_{\mathrm{y}}$; and $\sigma_{\text {ref }}^{\mathrm{s}}$ is defined by (see [6] for example)

$$
\beta \mathrm{V}_{0}=\left(\sigma_{\text {ref }}^{\mathrm{s}} / \sigma_{\mathrm{y}}\right) / \mathrm{f}\left(\sigma_{\text {ref }}^{\mathrm{s}} / \sigma_{\mathrm{y}}\right)
$$


where $\mathrm{V}_{0}$ is the value of $\mathrm{V}$ for pure secondary loading and is defined by

$$
\mathrm{V}_{0}=\mathrm{K}_{\mathrm{J}}^{\mathrm{s}} / \mathrm{K}_{\mathrm{I}}^{\mathrm{s}}
$$

again as used in R6; $\mathrm{f}\left(\sigma_{\text {ref }}^{\mathrm{s}} / \sigma_{\mathrm{y}}\right)$ is the R6 failure assessment curve function. Here, $\mathrm{K}_{\mathrm{J}}^{\mathrm{s}}$ is the plastically corrected value of $\mathrm{K}_{\mathrm{I}}^{\mathrm{s}}$ which can be evaluated from $\mathrm{J}^{\mathrm{s}}$, the value of the J-integral for secondary loads acting alone, by $K_{J}^{s}=\sqrt{E^{\prime} J^{s}}$ where $E^{\prime}$ is $E$ in plane stress and $E /\left(1-v^{2}\right)$ in plane strain. With these substitutions, in the elastic-plastic region Eq. (1) is replaced by

$$
Z^{\mathrm{s}}=\frac{E \varepsilon_{\text {ref }}^{\mathrm{s}}-\sigma_{\mathrm{ref}}^{\mathrm{s}}}{\beta \sigma_{\mathrm{y}}-\sigma_{\mathrm{ref}}^{\mathrm{s}}}=1+\frac{E \varepsilon_{\mathrm{ref}}^{\mathrm{s}}-\beta \sigma_{\mathrm{y}}}{\beta \sigma_{\mathrm{y}}-\sigma_{\text {ref }}^{\mathrm{s}}}
$$

where $\varepsilon_{\text {ref }}^{\mathrm{s}}=\varepsilon\left(\sigma_{\text {ref }}^{\mathrm{s}}\right)$. This expression for elastic follow-up factor has been used by Fujioka $[12,13]$, for example, for relaxation of displacement controlled loading in uncracked structures, by Fujioka [14] for cracked structures and more recently by Je et al. [15] for creep relaxation of crack-tip fields in cracked structures. Writing the expression for elastic follow-up in the form of the second part of Eq. (6) enables $Z^{\mathrm{s}}$ to be interpreted graphically in terms of the slope of the line joining the points $\mathrm{A}=$ $\left(\beta \sigma_{\mathrm{y}} / \mathrm{E}, \beta \sigma_{\mathrm{y}}\right)$ and $\mathrm{B}=\left(\varepsilon_{\mathrm{ref}}^{\mathrm{s}}, \sigma_{\mathrm{ref}}^{\mathrm{s}}\right)$, as shown in [12-15] and here in Fig. 1. This graphical interpretation is similar to that used to define $\mathrm{Z}$ in R5 [11]. The definition of elastic follow-up factor by Eq. (6) for secondary loading alone is used in the remainder of this paper and examined in detail in Section 3.

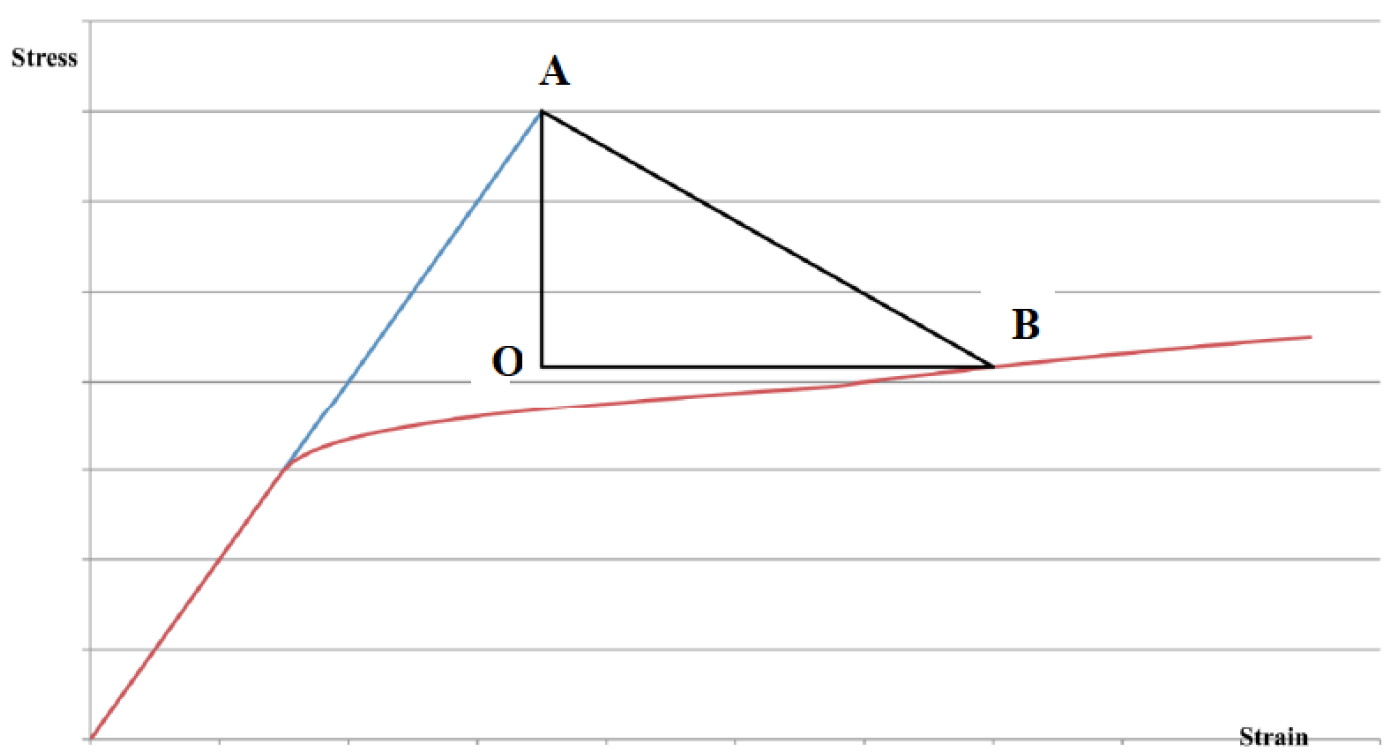

Fig. 1. Definition of elastic follow-up factor, $Z^{\mathrm{s}}$, for elastic-plastic response. The factor is defined by Eq. (6) using the slope of the hypotenuse of the black triangle; $Z^{\mathrm{s}}$ $=1+\mathrm{E}(\mathrm{OB} / \mathrm{OA})$ 
As $\varepsilon_{\text {ref }}^{\mathrm{s}} \geq \sigma_{\text {ref }}^{\mathrm{s}} /$ Eand $\sigma_{\text {ref }}^{\mathrm{s}}<\beta \sigma_{\mathrm{y}}$ Eq. (6) leads to $Z^{\mathrm{s}} \geq 0$. More typically it is expected that $Z^{\mathrm{s}} \geq 1$, with $\sigma_{\text {ref }}^{\mathrm{s}} \leq \beta \sigma_{\mathrm{y}}$ and $\varepsilon_{\text {ref }}^{\mathrm{s}} \geq \beta \sigma_{\mathrm{y}} / \mathrm{E}$, that is a negative slope of the hypotenuse in Figure 1. For plastic straining, $\varepsilon_{\text {ref }}^{\mathrm{s}}>\sigma_{\text {ref }}^{\mathrm{s}} / \mathrm{E}$, the limit $\sigma_{\text {ref }}^{\mathrm{s}}=\beta \sigma_{\mathrm{y}}$ corresponds to secondary stresses acting as primary and $\mathrm{Z}^{\mathrm{s}}=\infty$.

\section{ESTIMATE OF ELASTIC FOLLOW-UP FACTOR}

The estimate of $Z^{\mathrm{s}}$ in Eq. (6) is a function of $\beta, \sigma_{\text {ref }}^{\mathrm{s}} / \sigma_{\mathrm{y}}$ and the shape of the stressstrain curve. However, $\beta$ and $\sigma_{\text {ref }}^{\mathrm{s}} / \sigma_{\mathrm{y}}$ are related in R6 [5] to $\mathrm{V}_{0}$ by Eq. (4), which involves the failure assessment curve which also depends on the shape of the stressstrain curve. This means that $\mathrm{Z}^{\mathrm{s}}$ is related to the variation of $\mathrm{V}_{0}$ with $\beta$, for a given stress-strain curve, i.e. for a given material. This has been examined by Je et al. [15] and is set out more explicitly in Section 3.2. First, however, a discussion of the results of [12-15] is given in Section 3.1 to indicate the expected dependence of elastic follow-up on load magnitude.

\subsection{Discussion of the Results of Fujioka and Je et al.}

At small values of $\beta$ for which there is no plastic strain at the stress $\beta \sigma_{y}$, the cracked body response is essentially elastic with $\sigma_{\text {ref }}^{\mathrm{s}}=\beta \sigma_{\mathrm{y}}, \varepsilon_{\mathrm{ref}}^{\mathrm{s}}=\sigma_{\mathrm{ref}}^{\mathrm{s}} / \mathrm{E}$ and $\mathrm{V}_{0}=1$. In this case, $\mathrm{Z}$ cannot be determined by Eq. (6). For values of $\beta$ close to unity, the stress difference $\left(\beta \sigma_{\mathrm{y}}-\sigma_{\text {ref }}^{\mathrm{s}}\right)$ and the corresponding strain difference are small and hence it is unlikely that $\mathrm{Z}^{\mathrm{s}}$ can be determined with accuracy. This is shown in the elasticplastic numerical solutions of Fujioka [14], where large variations in elastic follow-up factor are obtained for a number of cases at low secondary loads. Therefore, higher values of secondary loading are required to determine a value of $\mathrm{Z}^{\mathrm{s}}$. At higher loads, the numerical results of [14] tend to be asymptotic to a constant value with increasing secondary stress, the asymptote being dependent on the stress index for a power-law material.

Results for elastic follow-up factor have also been obtained by Je et al. [15] for a cracked two-bar structure under displacement control. A range of crack sizes $(\mathrm{a} / \mathrm{t}=0.1,0.3,0.5)$ and Ramberg-Osgood description of plastic properties, with stress exponents $\mathrm{m}=5$ and 10 , were considered. From values of $\mathrm{J}$, and hence $\mathrm{V}_{0}$ from Eq. (5), Je et al. [15] used the elastic-plastic definition of elastic follow-up factor given by Eq. (6) and shown in Figure 1 and evaluated $Z^{s}$. They found values of $Z^{s}$ that were asymptotic to a constant value as the magnitude of the secondary loading was increased.

The asymptotic nature of the results of [12-15] for $\mathrm{Z}^{\mathrm{s}}$ may be explained as follows. Consider displacement-controlled loading of magnitude, $\Delta$. Then the elastic magnitude of the loading, $\beta$, is directly proportional to $\Delta$. For large values of $\Delta$, with response governed by fully plastic power-law behaviour with stress exponent, $\mathrm{m}$, elastic strains are negligible and hence $\varepsilon_{\text {ref }}^{\mathrm{s}} \propto \Delta, \sigma_{\text {ref }}^{\mathrm{s}} \propto \Delta^{1 / \mathrm{m}}$. At large enough $\Delta$, $\sigma_{\text {ref }}^{\mathrm{s}} \propto \Delta^{1 / \mathrm{m}} \ll<\sigma_{\text {ref }}^{\mathrm{s}, \mathrm{el}}=\beta \sigma_{\mathrm{y}} \propto \Delta$ (see Fig. 1) and hence Eq. (6) leads to a value of $Z^{\mathrm{s}}$ which is independent of $\Delta$; that is asymptotic to a constant value as the loading 
increases.

Je et al. also performed elastic-creep and elastic-plastic-creep analyses for power-law creep with stress exponents of 5 and 10 for the same load cases for which elasticplastic analyses had been performed. The resulting values of creep crack tip parameter, $\mathrm{C}(\mathrm{t})$, as a function of time, $\mathrm{t}$, were fitted by an expression which involves the elastic follow-up factor, $Z^{\mathrm{s}}$, for secondary loads alone given in [16]. This is a special case of a more general result for elastic-plastic-creep response under combined loading [17], Then $Z^{\mathrm{s}}$ was chosen as that value which led to a close fit of the solution of [16] to the numerical $\mathrm{C}(\mathrm{t})$ results from elastic-creep analyses The resulting values of $\mathrm{Z}^{\mathrm{s}}$ determined using this creep analysis of relaxation of the secondary loading were close to those from the elastic-plastic analysis. This gives confidence that the definition of elastic follow-up factor by Eq. (6) is reasonable as it leads to values consistent with those using established methods used in creep analysis.

\subsection{Explicit Expressions for $Z^{s}$}

In view of the above discussion, the definition of $\mathrm{Z}^{\mathrm{s}}$ by Eq. (6) is set out explicitly here for secondary loads acting alone. For large strains, the small-scale yielding corrections in the R6 Option 2 failure assessment curve may be neglected and this leads to the failure assessment curve being approximated by

$$
\mathrm{f}\left(\sigma_{\text {ref }}^{\mathrm{s}} / \sigma_{\mathrm{y}}\right)=\left[\mathrm{E} \varepsilon_{\text {ref }}^{\mathrm{s}} / \sigma_{\text {ref }}^{\mathrm{s}}\right]^{-1 / 2}
$$

where the secondary reference stress is related to the associated value of $\mathrm{J}$ and is defined by Eqs. (4-5).

For a Ramberg-Osgood material, the total strain is related to stress by

$$
\varepsilon\left(\sigma_{\text {ref }}^{\mathrm{s}}\right)=\frac{\sigma_{\text {ref }}^{\mathrm{s}}}{\mathrm{E}}+\alpha\left(\frac{\sigma_{\mathrm{ref}}^{\mathrm{s}}}{\sigma_{\mathrm{y}}}\right)^{\mathrm{m}}
$$

where the multiplying constant $\alpha$ is chosen as $\alpha=0.002$ to ensure that $\sigma_{y}$ is the $0.2 \%$ proof stress. Hence,

$$
\operatorname{E\varepsilon }\left(\sigma_{\text {ref }}^{\mathrm{s}}\right) / \sigma_{\mathrm{y}}=\left(\frac{\sigma_{\text {ref }}^{\mathrm{s}}}{\sigma_{\mathrm{y}}}\right)+\frac{E \alpha}{\sigma_{\mathrm{y}}}\left(\frac{\sigma_{\text {ref }}^{\mathrm{s}}}{\sigma_{\mathrm{y}}}\right)^{\mathrm{m}}
$$

and

$$
\operatorname{E\varepsilon }\left(\sigma_{\text {ref }}^{\mathrm{s}}\right) / \sigma_{\text {ref }}^{\mathrm{s}}-1=\frac{E \alpha}{\sigma_{\mathrm{y}}}\left(\frac{\sigma_{\text {ref }}^{\mathrm{s}}}{\sigma_{\mathrm{y}}}\right)^{\mathrm{m}-1}
$$

Combining Eq. (4) with Eqs. $(7,10)$ leads to 


$$
\beta \mathrm{V}_{0}=\left[1+\left(\frac{\mathrm{E} \alpha}{\sigma_{\mathrm{y}}}\right)\left(\frac{\sigma_{\mathrm{ref}}^{\mathrm{s}}}{\sigma_{\mathrm{y}}}\right)^{\mathrm{m}-1}\right]^{1 / 2}\left(\frac{\sigma_{\mathrm{ref}}^{\mathrm{s}}}{\sigma_{\mathrm{y}}}\right)
$$

This may be solved for $\left(\sigma_{\text {ref }}^{\mathrm{s}} / \sigma_{\mathrm{y}}\right)$ for given $\beta \mathrm{V}_{0}$ and given material constants. More generally, Eqs. $(4,7)$ may be used to relate $\beta \mathrm{V}_{0}$ to $\left(\sigma_{\text {ref }}^{\mathrm{s}} / \sigma_{\mathrm{y}}\right)$ provided the stress-strain curve is defined. For a given value of $Z^{s}$, a relationship between $\beta$ and $V_{0}$ for given material constants is then obtained using Eq. (6). Some sample results are shown for $Z^{s}=3$ in Fig. 2. It can be seen that the dependence of $V_{0}$ on $\beta$ is relatively weakly affected by material properties. Results in Fig. 3 show, however, that the dependence is strongly affected by the magnitude of elastic follow-up factor. This suggests that an estimate of $Z^{s}$ could be made without the need to consider the material properties in detail and this is examined in Section 3.3. The observations for the dependence of $\mathrm{V}_{0}$ on $\beta$ have also been made from numerical results in Je at al. [15] who also note that "values of $\mathrm{V}_{0}$ generally increase with increasing $\mathrm{Z}^{\mathrm{s}}$; for $\mathrm{Z}^{\mathrm{s}} \leq 2$, they decrease monotonically with increasing $\beta$ [this is simply stated in [15] but shown to apply in Section 3.3. below]; for $Z^{s}>2$, they increase with increasing $\beta$ up to a certain value where values of $\mathrm{V}_{0}$ reach a maximum and then decrease; the value of $\beta$ at which the maximum value of $\mathrm{V}_{0}$ occurs increases with increasing $\sigma_{\mathrm{y}} / \mathrm{E}$, but the maximum value of $\mathrm{V}_{0}$ is almost independent of $\sigma_{\mathrm{y}} / \mathrm{E}$ ”. These trends are also shown in Figs. 2, 3.

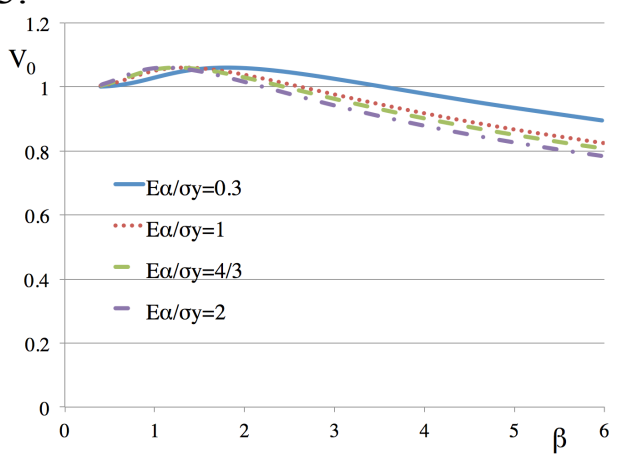

(a)

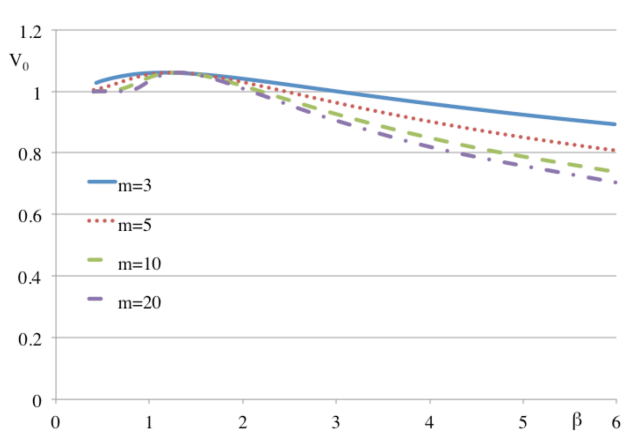

(b)

Fig. 2. Dependence of $\mathrm{V}_{0}$ on the normalised magnitude of the secondary loading, $\beta$, for $Z^{s}=3$ for a range of material properties: (a) for a number of values of $E \alpha / \sigma_{y}$ for $\mathrm{m}=5$; (b) for a number of values of $\mathrm{m}$ for $\mathrm{E \alpha} / \sigma_{\mathrm{y}}=4 / 3$. 


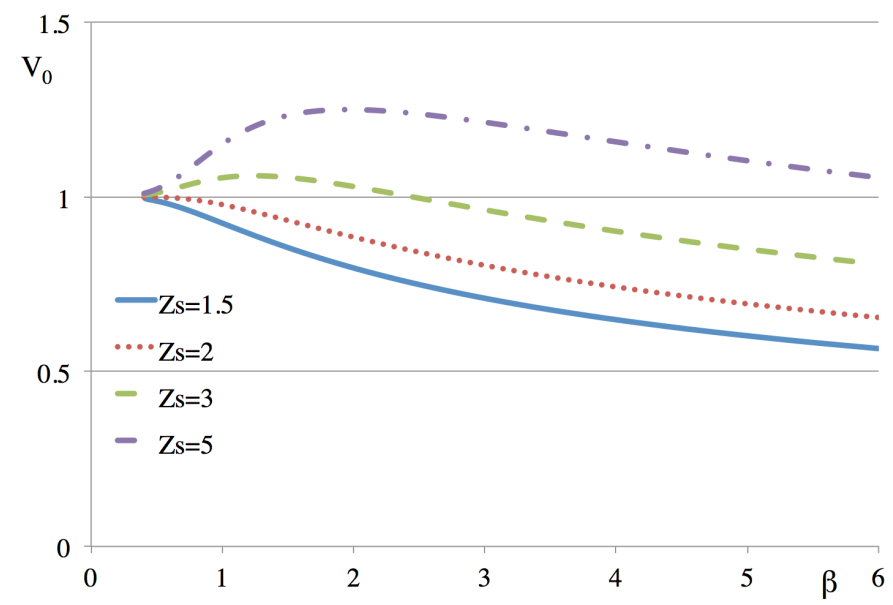

Fig. 3. Dependence of $V_{0}$ on the normalised magnitude of the secondary loading, $\beta$, for $\mathrm{m}=5$ and $E \alpha / \sigma_{\mathrm{y}}=4 / 3$ for a number of values of elastic follow-up factor, $Z^{\mathrm{s}}$.

\subsection{Estimate of $Z^{\text {s }}$ from the R6 Option 1 Failure Assessment Curve}

It was noted in Section 3.2 that the dependence of $\mathrm{V}_{0}$ on $\beta$ is relatively weakly affected by material properties but is strongly dependent on the magnitude of elastic follow-up factor. Therefore, here an estimate of elastic follow-up factor is based on the R6 Option 1 failure assessment curve, without considering the stress-strain curve in detail. The Option 1 failure assessment curve is given in [5] and is here denoted $\mathrm{f}_{1}$ :

$$
f_{1}(x)=\left(1+0.5 x^{2}\right)^{-1 / 2}\left[0.3+0.7 \exp \left(-0.6 x^{6}\right)\right]
$$

where the variable $\mathrm{x}$ is taken as the load parameter $\mathrm{L}_{\mathrm{r}}$ to construct the failure assessment diagram in R6 [5]. Instead, setting $x=\sigma_{\text {ref }}^{\mathrm{s}} / \sigma_{\mathrm{y}}$, Eq. (4) becomes

$$
\beta \mathrm{V}_{0}=\mathrm{x} / \mathrm{f}_{1}(\mathrm{x})
$$

and Eq. (7) is

Hence, from Eq. (6)

$$
\operatorname{E\varepsilon }\left(\sigma_{\text {ref }}^{\mathrm{s}}\right) / \sigma_{\mathrm{y}}=\mathrm{x} / \mathrm{f}_{1}^{2}(\mathrm{x})
$$

$$
\beta=x+\frac{1}{Z^{s}}\left(\frac{x}{f_{1}^{2}(x)}-x\right)
$$

Thus, for any value of $\beta$, it is possible to derive a value of $x$ from Eq. (15) for given $\mathrm{Z}^{\mathrm{s}}$ and hence a value of $\mathrm{V}_{0}$ from Eq. (13).

Eqs. $(13,15)$ can easily be solved numerically using Eq. (12). The solution for $Z^{s}=1$ is particularly simple in form as it leads to $\mathrm{V}_{0}=\mathrm{f}_{1}(\mathrm{x})$ which is always less than unity. As noted in [6], at the other extreme, very large follow-up corresponds to $\beta=\mathrm{x}$ and $\mathrm{V}_{0}=1 / \mathrm{f}_{1}(\mathrm{x})(\geq 1)$. For $\mathrm{Z}^{\mathrm{s}}=2, \mathrm{~V}_{0}=2 \mathrm{f}_{1} /\left(1+\mathrm{f}_{1}^{2}\right)$ from Eqs. $(13,15)$ so that $\mathrm{V}_{0} \leq 1, \mathrm{f}_{1} \leq 1$ 
(indeed this would apply for any failure assessment curve f), consistent with the statements in [15].

Some results from solving Eqs. $(13,15)$ are shown in Fig. 4 for a number of values of $\mathrm{Z}^{\mathrm{s}}$. The close agreement with Fig. 3 is clear, confirming the weak dependence on material properties.

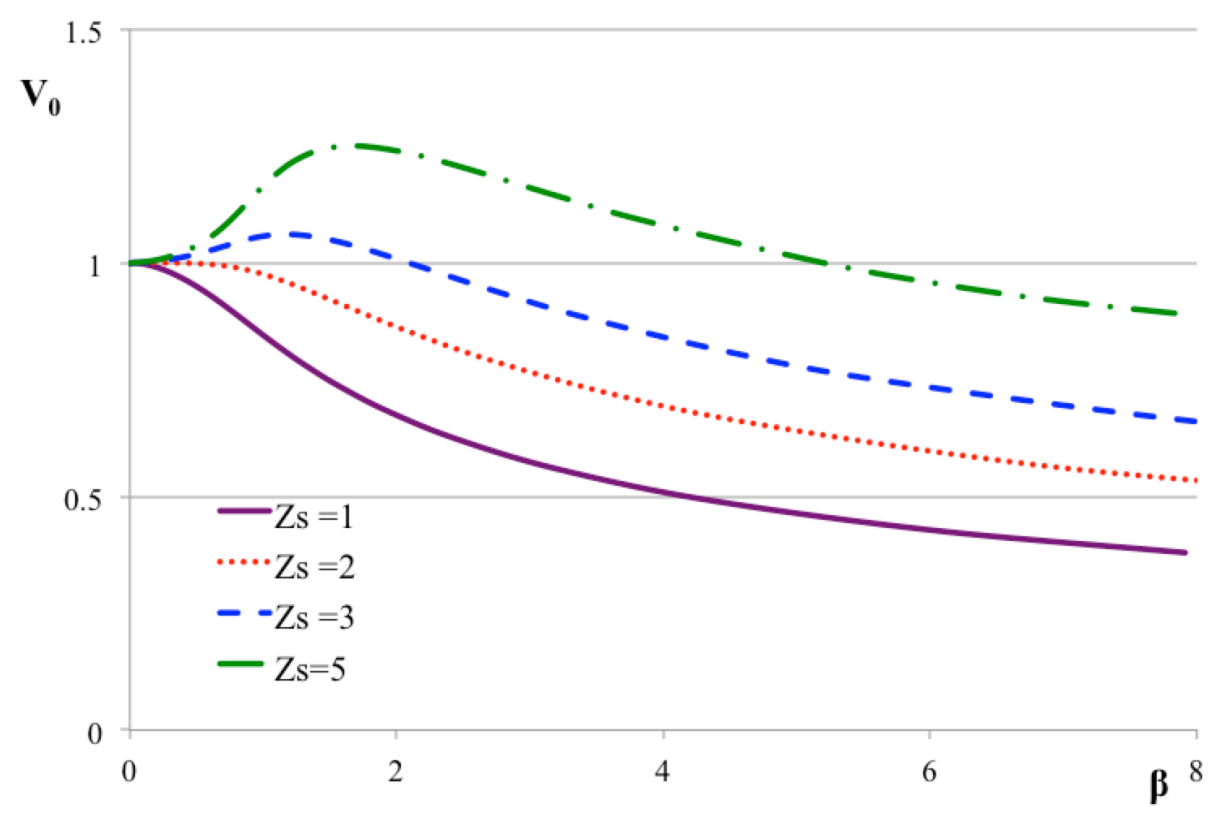

Fig. 4. Dependence of $\mathrm{V}_{0}$ on the normalised magnitude of the secondary loading, $\beta$, based on the R6 Option 1 failure assessment curve.

The results in Fig. 4 may be used to develop the relationship between $Z^{s}$ and $V_{0}$ for any particular magnitude of secondary loading, $\beta$, and sample results are presented in Fig. 5. The dependence on $\beta$ is not strong.

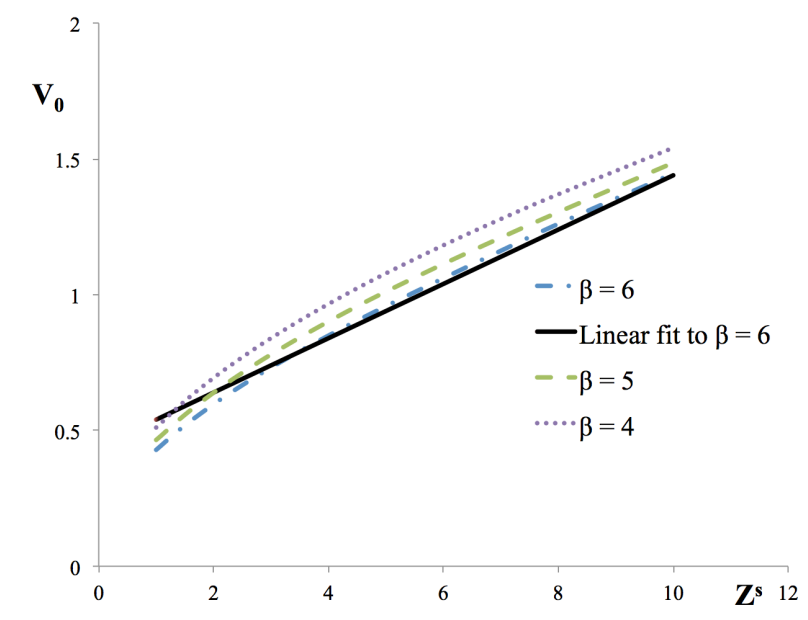

Fig. 5. Relationship between $\mathrm{Z}^{\mathrm{s}}$ and $\mathrm{V}_{0}$ derived using the $\mathrm{R} 6$ Option 1 failure assessment curve, for several magnitudes of secondary loading, $\beta$. Also shown is a linear fit to the results for $\beta=6$. 
For moderate elastic follow-up, $\mathrm{Z}^{\mathrm{s}} \leq 3, \mathrm{R} 6$ [5] provides an estimate of $\mathrm{V}$ independent of the level of elastic follow-up as discussed in Section 4 below. For very large elastic follow up, $Z^{s} \geq 10$ say, secondary loads can be treated as primary without introducing excessive conservatism. Therefore, it is of interest to estimate $V_{0}$ for intermediate levels of elastic follow-up. It can be seen from Fig.5 that the relationship between $Z^{s}$ and $V_{0}$ is approximately linear in the range $Z^{\mathrm{s}}$ from 3 to 10 . The fit

$$
\mathrm{Z}^{\mathrm{s}}=10 \mathrm{~V}_{0}-4.4 ; \quad \beta=6
$$

for example, is within $3.6 \%$ of the numerical results for this range of $\mathrm{Z}^{\mathrm{s}}$. Similar fits could be produced for other values of $\beta$ but as there is not a strong dependence on $\beta$, a possible approach would be to evaluate $V_{0}$ for a secondary stress of elastic magnitude $\beta=6$ and then to estimate $Z^{\text {s }}$ from Eq. (16), provided the result is in the range 3 to 10 . This provides a practical method for estimating the elastic follow-up factor from an elastic-plastic analysis for a large secondary loading, as noted in [15], and would provide a conservative approach for smaller magnitudes of secondary loading. This is examined in part 2 [8].

\section{TREATMENT OF COMBINED LOADING}

Section 3 has considered secondary stresses acting alone. Whether or not the estimate of elastic follow-up factor, $Z^{\mathrm{s}}$, obtained for secondary loads alone is adequate for use as a value of follow-up factor, $Z$, in the treatment of combined loading depends on the method adopted to treat combined loading. For essentially strain-controlled loading, $\mathrm{Z}=1$, Section II.6 of R6 [5] suggests that it is adequate to use the estimate

$$
\mathrm{V}^{(1)} / \mathrm{V}_{0}=\mathrm{f}\left(\mathrm{L}_{\mathrm{r}}\right), \quad \mathrm{Z}=1
$$

to evaluate the parameter $K_{r}$. Here $f\left(L_{r}\right)$ defines the shape of the failure assessment curve such as the Option 1 curve of Eq. (12). As a number of estimates of $\mathrm{V}$ are presented in this section, these are denoted $\mathrm{V}^{(\mathrm{n})}, \mathrm{n}=1, \ldots, 7$, in order to distinguish them from each other. For moderate elastic follow-up, $\mathrm{Z} \leq 3$, R6 provides a simplified estimate

$$
\mathrm{V}^{(2)} / \mathrm{V}_{0}=\mathrm{f}\left(\mathrm{L}_{\mathrm{r}}\right)+0.42 \mathrm{~L}_{\mathrm{r}}\left(0.72+\mathrm{L}_{\mathrm{r}}\right)\left[\mathrm{f}\left(\mathrm{L}_{\mathrm{r}}\right)\right]^{2}, \quad \mathrm{Z} \leq 3
$$

and gives the estimate

$$
\mathrm{V}^{(3)} / \mathrm{V}_{0}=\mathrm{f}\left(\mathrm{L}_{\mathrm{r}}\right)+\frac{3}{4} \frac{\mathrm{Z}-1}{\mathrm{Z}} \mathrm{L}_{\mathrm{r}}\left(\beta+\mathrm{L}_{\mathrm{r}}\right)\left[\mathrm{f}\left(\mathrm{L}_{\mathrm{r}}\right)\right]^{2} / \mathrm{V}_{0}, \quad \mathrm{Z}>3, \mathrm{~L}_{\mathrm{r}}+\beta \leq 0.7
$$

for $Z>3$ and small loadings for which $L_{r}+\beta \leq 0.7$. The derivation of these expressions is given in [6]. For larger combinations of primary and secondary loading, when large values of $Z$ are obtained, further estimates have been in [18]. The derivations of those estimates are omitted here for brevity and some are simply listed below. 


$$
\frac{V^{(4)}}{V_{0}}=f\left(L_{r}\right)+\frac{Z-2}{Z} h_{1}\left(L_{r}, \beta\right), \text { for large } Z
$$

where

$$
h_{1}\left(L_{r}, \beta\right)=\frac{\left(L_{r}+\beta\right) f\left(L_{r}\right) f(\beta)}{\beta f\left(L_{r}+\beta\right)}-\frac{L_{r} f(\beta)}{\beta}-f\left(L_{r}\right)
$$

reproduces the load-controlled solution in [6] for $\mathrm{Z}=\infty$ and is considered a potential, conservative estimate for large $\mathrm{Z}$. The solution

$$
V^{(5)} / V_{0}=f\left(L_{r}\right)+\frac{Z-2}{Z} A\left[f\left(\beta+L_{r}\right)\right]^{1.18} f\left(L_{r}\right) f(\beta) / \beta
$$

with

$$
A=\frac{L_{r}+\beta}{\left[f\left(L_{r}+\beta\right)\right]^{2}}-\frac{L_{r}}{\left[f\left(L_{r}\right)\right]^{2}}-\frac{\beta}{[f(\beta)]^{2}}
$$

is considered to be particularly accurate for large secondary loads. Another solution

$$
\frac{V^{(6)}}{V_{0}}=f\left(L_{r}\right)+\left[\frac{Z\left[f\left(\beta+L_{r}\right)\right]^{2}-2}{2 Z}\right]\left[\frac{\operatorname{Af}\left(L_{r}\right) f(\beta)}{\beta f\left(\beta+L_{r}\right)}\right]\left[\frac{1+\left(\beta+L_{r}\right)^{2}}{1+0.5\left(\beta+L_{r}\right)^{2}}\right]
$$

again with

$$
A=\frac{L_{r}+\beta}{\left[f\left(L_{r}+\beta\right)\right]^{2}}-\frac{L_{r}}{\left[f\left(L_{r}\right)\right]^{2}}-\frac{\beta}{[f(\beta)]^{2}}
$$

is shown in [18] to have improved accuracy compared to Eq. (21) for small secondary loads but tends to be over-conservative at large secondary loads.

It is apparent from the above that there are a large number of potential methods for estimating V, equivalent to estimating J. Furthermore, a number of these methods require an estimate of the elastic follow-up factor, Z. Part 2 of this paper [8] examines the accuracy of the above estimates when $Z^{s}$ is used as an estimate of $Z$, that is if $J$ can be estimated without a separate estimate of elastic follow-up under combined primary and secondary.

In assessing numerical results, it is worth noting from [6] that the ratio of two estimates, $\mathrm{K}_{\mathrm{J}}^{(\mathrm{i})}$ and $\mathrm{K}_{\mathrm{J}}^{(\mathrm{j})}$, of $\mathrm{K}_{\mathrm{J}}$, the stress intensity factor equivalent of $\mathrm{J}$, corresponding to two estimates $\mathrm{V}^{(\mathrm{i})}$ and $\mathrm{V}^{(\mathrm{j})}$ of $\mathrm{V}$, for given primary and secondary loading is

$$
\frac{\mathrm{K}_{\mathrm{J}}^{(\mathrm{i})}}{\mathrm{K}_{\mathrm{J}}^{(\mathrm{j})}}=\frac{\mathrm{L}_{\mathrm{r}}+\beta \mathrm{V}^{(\mathrm{i})}}{\mathrm{L}_{\mathrm{r}}+\beta \mathrm{V}^{(\mathrm{j})}}
$$


Therefore, in some cases (for example, $\beta<\mathrm{L}_{\mathrm{r}}$ ) the result may not be sensitive to the estimate of $\mathrm{V}$ and hence to the estimate of $\mathrm{Z}$.

\section{CLOSING REMARKS}

A method in the literature for estimating an elastic follow-up factor, $Z^{\text {s }}$, for cracked structures under secondary stresses acting alone in the elastic-plastic regime has been examined. It has been shown that the method has a similar graphical interpretation to that used in high temperature assessment procedures, such as R5 [11], to estimate elastic follow-up in creeping structures. Finite element values of $Z^{\mathrm{s}}$ from the elasticplastic analysis have been found to be close to those determined using creep analysis of relaxation of secondary loading [15]. This gives confidence that the definition of elastic follow-up factor using the elastic-plastic method is reasonable as it leads to values consistent with those using established methods used in creep analysis.

In this paper it has been shown that $\mathrm{Z}^{\mathrm{s}}$ is related to the variation with magnitude of secondary loading of the parameter $\mathrm{V}_{0}$ used in R6 [5] to quantify plasticity effects on $\mathrm{J}$ for secondary stresses acting alone. A simple formula for estimating the elastic follow-up factor from a single calculation leading to a value of $\mathrm{V}_{0}$ has been proposed.

Whether the estimate of elastic follow-up factor, $Z^{\mathrm{s}}$, obtained for secondary loads alone can also be used as a value of follow-up factor, $\mathrm{Z}$, in the treatment of combined loading depends on the method adopted to treat combined loading. A number of estimates of $\mathrm{J}$ for combined loading, written in terms of the equivalent parameter $\mathrm{V}$ used in R6, have been presented in this paper. Part 2 of the paper [8] examines the accuracy of these estimates for combined loading by comparison with detailed finite element solutions for geometries, crack sizes and material properties leading to a range of values of elastic follow-up in order to develop practical proposals for treating elastic follow-up in fracture assessments under combined loading. 
[1] Ainsworth RA. The treatment of thermal and residual stresses in fracture assessments. Engng Fract Mech 1986;24:65-76.

[2] Ainsworth RA, Sharples JK, Smith SD. Effects of residual stresses on fracture behaviour - experimental results and assessment methods. J Strain Anal2000;35:307-16

[3] Oh C-Y, Kim Y-J, Budden PJ, Ainsworth RA. Biaxial stress effects on estimating J under combined mechanical and thermal stresses. Int J Pres Ves Piping 2011;88:365-74.

[4] BS7910:2005, Guide to methods for assessing the acceptability of flaws in metallic structures, incorporating Amendment 1, British Standards

[5] R6 Revision 4, Assessment of the Integrity of Structures Containing Defects, Amendment 11, EDF Energy Nuclear Generation, Gloucester (2015).

[6] Ainsworth RA. Consideration of elastic follow-up in the treatment of combined primary and secondary stresses in fracture assessments, Engng Fract Mech 2012;96,558-569.

[7] Song T-K, Oh C-Y, Kim Y-J, Ainsworth RA, Nikbin K. Approximate J estimates for combined primary and secondary stresses with large elastic follow-up, Int J Pres Ves Piping 2013; 111-112, 217-231.

[8] Lee H-J, Kim Y-J, Ainsworth RA, Oh C-Y. Fracture assessments with elastic follow-up for combined primary and secondary loadings. Part 2: numerical validation, Engng Fract Mech 2019, submitted for publication.

[9] Robinson EL. Steam-piping design to minimise creep concentrations. Transactions of the American Society of Mechanical Engineers, $1955 ; 77,1147-1162$.

[10] Boyle JT, Nakamura K. The assessment of elastic follow-up in high temperature piping systems-Overall survey and theoretical aspects. Int J Pres Ves Piping 1987;29,167-194.

[11] R5 Issue 3, Revision 002, Assessment Procedure for the High Temperature Response of Structures, EDF Energy Nuclear Generation, Gloucester (2014).

[12] Fujioka T, Elastic follow-up behavior in power law type inelastic bodies and simplified assessment methods of peak strain and peak stress relaxation due to displacement-controlled loading. Trans JSME, Ser A, 2008;74,No 738 (in Japanese).

[13] Fujioka T. Analytical expression of elastic follow-up factors in fully-plastic situation for creep-fatigue damage assessment of high temperature components. Proceedings of the ASME Pressure Vessels and Piping Conference, Paper PVP2016-63031, ASME, New York, 2016.

[14] Fujioka T. Simplified estimate of elastic-plastic J-integral of cracked components subjected to secondary stresses by the enhanced reference stress method and elastic follow-up factors. Int J Pres Ves Piping 2013;108-109,2839. 
[15] Je J-H, Kim Y-J, Lee K-H, Jerng D-W. A simple method to estimate elastic follow-up factors for transient creep parameter $\mathrm{C}(\mathrm{t})$ under secondary stress. $\mathrm{J}$ Strain Analysis, 2016;51,336-346.

[16] R A Ainsworth, Singular fields at defects in creeping structures subjected to mechanical loading combined with thermal stresses, in Behaviour of Defects at High Temperatures, Sheffield (1992); Proceedings ESIS 15, eds R A Ainsworth and R P Skelton, MEP, London, 423-439 (1993).

[17] R A Ainsworth, D W Dean and P J Budden, Creep and creep-fatigue crack growth for combined loading: extension of the advice in R5 Volume 4/5 Appendix A3, EDF Energy Nuclear Generation Report E/REP/BDBB/0059/GEN/04 Revision 004 (2015).

[18] R A Ainsworth, Further analysis of fracture under combined primary and secondary loading with elastic follow-up, EDF Energy Nuclear Generation Report E/REP/BBGB/0126/GEN/14 (2014). 